\title{
Definition of two-dimensional condensation via BEM, using the Glaser method approach
}

\author{
Nuno Simões, Fernando Branco, António Tadeu* \\ Department of Civil Engineering, Faculty of Sciences and Technology, University of Coimbra, Polo II-Pinhal de Marrocos, 3030-290 Coimbra, Portugal.
}

Received 9 May 2001; revised 3 January 2002; accepted 17 January 2002

\begin{abstract}
This work describes an iterative technique for the definition of condensation across two-dimensional elements via the boundary element method (BEM). Initially, the BEM is used to calculate the steady-state conduction of heat and vapour diffusion, discretizing only the boundary materials' discontinuities. Then, a small sub-domain is defined, where condensation develops; that is, where the vapour pressure exceeds the vapour saturation pressure. Using the Glaser approach, the vapour pressure is equalised to the vapour saturation pressure, and then the vapour equilibrium is redefined by means of the BEM solution. This process is repeated until all sub-domains where vapour pressure exceeds vapour saturation pressure are eliminated.

The method is first implemented and validated by applying it to a simple one-dimensional hygrothermal problem, for which the solution is calculated analytically. The applicability of the proposed method is then illustrated by computing the two-dimensional condensation across a T shaped element, for different boundary conditions. C) 2002 Elsevier Science Ltd. All rights reserved.
\end{abstract}

Keywords: Temperature; Vapour pressure; Heat transfer; Moisture diffusion; Condensation

\section{Introduction}

Several kinds of pathology may be caused by condensation [1], from the appearance of moulds to the deterioration of the building material itself. To avoid the hazardous effects of condensation, its presence must be detected, and corrective measures taken [2].

Ideally, the risk of condensation inside building elements should be identified during the design phase, before construction. Several methods have been proposed to deal with this problem, described by Glaser [3-5], Krischer [6], Luikov [7], and Philip and De Vries [8], based on fluid mechanics using the well known mathematical models of Fourier (heat conduction), Fick (moisture diffusion) and Darcy (water diffusion). For a good review of the Fourier, Fick and Darcy laws, see also, Carslaw et al. [9], Crank [10] and Gebhart [11].

Krischer [6] studied the moisture movements in porous materials under the influence of temperature gradients. He identified two transport mechanisms for material moisture, one being the vapour diffusion and the other being described as capillary water movement. Luikov and Philip et al. [7,8]

\footnotetext{
* Corresponding author. Tel.: +351-239-797-204; fax: +351-239-797190.

E-mail address: tadeu@dec.uc.pt (A. Tadeu).
}

worked with porous material, defining moisture transport using methods based on the thermodynamics of irreversible processes. For an extensive review on these methods, we refer readers to the work of Kieß1 [12], Kieß1 et al. [13] and Künzel [14].

The Glaser method is based on a number of assumptions, namely, that the moisture is transported in accordance with Fick's law, the transport of heat obeys the Fourier law, the process occurs under steady-state conditions, the building elements are airtight and that there is no migration of condensed moisture. The material properties are taken to be constant, even under condensation conditions. Condensation is assumed to occur when the vapour pressure equals the saturated vapour pressure (the maximum vapour pressure allowed).

The Glaser method only takes into account the vapour transport in building components; it does not take into account the effects of liquid transport. In spite of the simplifications assumed by this method, it is used frequently to solve civil engineering problems related to the identification of internal condensation risks. The method of Glaser is even proposed by the DIN 4108 [15] and prEN ISO 13788 [16] standards to define condensation. Most of the models that have been developed based on the Glaser approach rely on a simple one-dimensional mathematical formulation. This procedure is adequate if the wall is straight, with constant 
thickness and subject to uniform state conditions on both sides. However, there are situations where a one-dimensional formulation is not accurate enough. In these cases, different numerical techniques, such as the finite elements [17] and finite difference methods [18], have been used to model and analyse the problem. These methods require analysis of the fully discretized domain, leading to very complex computational numerical schemes.

To avoid this drawback, the present paper proposes the use of the boundary element method (BEM). The BEM allows a compact description of the medium in terms of boundary elements at the material discontinuities alone. Although the BEM leads to a fully populated system of equations, contrary to the sparse system given by the finite difference and finite element techniques, the efficiency of the technique lies in the reduced computational effort required, given the substantial reduction of the size of the linear system of equations that needs to be solved. As is well known, the BEM is based on the use of appropriate fundamental solutions, or Green's functions, relating the field variables in a homogeneous medium to point sources placed somewhere within it. The fundamental solution most often used is that of an infinite homogeneous space, because it is known in closed-form and has a relatively simple structure.

The BEM has already been used to solve heat and moisture diffusion. Mingfang et al. [19] used the BEM to analyse the thermal characteristics of a column in contact with an insulated floor under steady-state conditions. Fratantonio et al. [20] have analytically calculated the boundary element integrals required for solving two-dimensional problems governed by the Laplace equation, for different orders of interpolation functions. Kassab et al. [21] have proposed a generalized boundary integral equation for isotropic heat conduction with spatially varying thermal conductivity. Ochiai et al. [22] used a multiple-reciprocity analysis to study steady heat conduction. Melnikov [23] presented Green's functions for two-dimensional heat conduction on thin plates of simple configuration.

The present work uses the BEM to define condensation areas in two-dimensional spaces using an iterative scheme. First, the vapour pressure equilibrium and the saturation pressure are defined across the two-dimensional element being analysed. Then, an iterative process is used to define, in each iteration, a small sub-domain where condensation occurs, i.e. where the vapour pressure is greater than the vapour saturation pressure. The vapour pressure is rendered equal to the vapour saturation pressure along this subdomain, using the Glaser approach. A new vapour equilibrium is then defined using the BEM solution. This iterative process is repeated until there is no sub-domain across the element where the vapour pressure exceeds the vapour saturation pressure. Finally, once the full domain suffering condensation has been determined, the condensed vapour moisture is quantified inside each small sub-domain. As pointed out earlier, the method does not consider the transport mechanism of water and the changes in property of the material. However, this simplification method is frequently adopted in practical design and is indicated by several standards.

The type of problem solved here has been solved before using other iterative schemes based on the Finite Differences and Finite Element Methods, which require the full discretization of the domain. Furthermore, the models used to account for the condensed vapour moisture often use a one-dimensional discretization and do not quantify the variation of condensed vapour along the domain.

The present article is organized as follows: first, a brief definition of the problem is given, and then the BEM is formulated, indicating the Green's functions required. The iterative process for defining the condensations using the Glaser approach is described. The results are then validated using a model of a two-dimensional wall subjected to onedimensional steady-state heat and vapour pressure diffusion, for which an analytical solution is defined. The applicability of the proposed method is then illustrated by computing the two-dimensional condensation across a T-shaped element, for different boundary conditions.

\section{Definition of the problem}

This work aims to define sub-domains where condensation occurs across a construction element subjected to prescribed temperature and moisture boundary conditions. The moisture diffusion is determined assuming that no vapour pressure at any point can be greater than the vapour saturation pressure. After the definition of the condensation sub-domain, the amount of condensed moisture will be quantified. The Glaser assumptions will be followed.

\subsection{BEM formulation}

Consider an isotropic and homogeneous medium with prescribed vapour pressure and vapour fluxes along its boundary. If one assumes that there is no moisture generation inside the domain being analysed, then the vapour pressure equilibrium is governed by the Laplace equation:

$$
\frac{\partial^{2} P}{\partial x^{2}}+\frac{\partial^{2} P}{\partial y^{2}}=0
$$

where $P$ is the vapour pressure and $x$ and $y$ are the coordinates in the Cartesian axis system. In the present case, where vapour diffusion is studied, Fick's law expresses the vapour diffusion by

$\vec{g}=-\pi \vec{\nabla} P_{\mathrm{w}}$

where $\pi$ is the material's permeability and

$\vec{\nabla} P_{\mathrm{w}}=\frac{\partial P_{\mathrm{w}}}{\partial x} \vec{e}_{1}+\frac{\partial P_{\mathrm{w}}}{\partial y} \vec{e}_{2}$

is the vapour pressure gradient.

However, the maximum vapour pressure that may occur 
at any point is the vapour saturation pressure, which holds for water vapour and is a function of temperature at each point, according to the BS 5250 [24],

$P_{\mathrm{s}}=610.5 \exp ((17.269 T) /(237.3+T))$

where $T$ is the temperature in ${ }^{\circ} \mathrm{C}$.

Since the saturation pressure depends on the temperature, it is necessary to determine the temperature distribution along the domain being studied. Temperature conduction in a steady-state isotropic medium with no internal heat generation is also governed by a Laplace equation. For a two-dimensional heat conduction problem, the following equation applies:

$\frac{\partial^{2} T}{\partial x^{2}}+\frac{\partial^{2} T}{\partial y^{2}}=0$

where $T$ is the temperature and $x$ and $y$ define the Cartesian coordinate system used.

The heat flow is then given by the Fourier law:

$\vec{q}=-k \vec{\nabla} T$

where $k$ is the conductivity of the material that is assumed to be independent of temperature, and

$\vec{\nabla} T=\frac{\partial T}{\partial x} \vec{e}_{1}+\frac{\partial T}{\partial y} \vec{e}_{2}$

is the temperature gradient.

Thus, the definition of the vapour and vapour saturation pressure across the element analysed requires the solution of a pressure and a temperature equilibrium problem. This solution is obtained using the BEM, which requires the discretization of the element boundary alone.

Given the amount of existing literature on the BEM solution of heat and moisture transfer problems under steadystate conditions [25], only a brief description of the BEM equations relevant to its application to this type of problem is given here.

It is sufficient to say that the application of boundary elements to this type of problem requires the integration of Green's functions and their derivatives for all the elements used to discretize the boundaries of the model [26], as follows:

$G^{k l}=\int_{C_{l}} \phi G\left(x_{k}, x_{l}\right) \mathrm{d} C_{l}$

$H^{k l}=\int_{C_{l}} \phi H\left(x_{k}, x_{l}, n_{l}\right) \mathrm{d} C_{l}$

where $G\left(x_{k}, x_{l}\right)$ is the component of the Green's function for temperature or moisture, $H\left(x_{k}, x_{l}, n_{l}\right)$ the corresponding flux component at $x_{k}$ due to a concentrated load at $x_{l}, n_{l}$ the normal outward unit for the $l$ th boundary segment $C_{l}$, and $\phi$ is an interpolation function.

The free space Green's function assumed in the present case is [26],

$G\left(x, x_{0}\right)=\frac{1}{2 \pi \lambda} \ln (1 / r)$

where $\lambda$ is the thermal conductivity or moisture permeability of the material, which is taken to be constant and $r$ is the distance between the source and the receiver.

If one takes the partial derivatives of $G$ in relation to the unit outward normal direction $n$ and applies the Fourier/ Fick's law, the expressions for the flux components are given by

$H\left(x, x_{0}, n_{l}\right)=-\frac{1}{2 \pi} \frac{\partial \ln (1 / r)}{\partial n}$

When the integrations, given by Eqs. (6) and (7), are performed along the loaded element, the integrands exhibit a singularity, but the integrations can be performed analytically. When the integration is not along the loaded element, the integrations are performed using a standard Gaussian quadrature scheme with 12 points.

After the integral equations have been subjected to the boundary conditions, a system of equations is defined which can be solved for the nodal temperature or moisture, and heat or moisture fluxes. Once the nodal values along the boundary are known, values for the problem variable analysed (temperature or vapour pressure), or its derivatives at any point in the domain, can be obtained.

\section{Iterative process}

The process starts by defining the vapour saturation pressure from the equilibrium of temperatures across the construction element being analysed, over a fine grid of receivers, establishing the boundary temperature conditions. Then, the first estimation of the vapour pressure over the same grid of receivers is performed, prescribing the known boundary vapour pressure conditions. At this stage, if all receivers register a vapour pressure $\left(P_{\mathrm{w}}\right)$ lower than the vapour saturation pressure $\left(P_{\mathrm{s}}\right)$, this estimated distribution is the final one.

If the receivers record an amount of $P_{\mathrm{w}}$ that exceeds $P_{\mathrm{s}}$, a second iteration is performed over a modified model. First, the receiver whose estimated pressure value most exceeds the corresponding saturation pressure is identified. Then, a small sub-domain (quadrilateral cell) is defined around this receiver. The accuracy of the solution was tested by placing a varied number of boundary elements to define this new cell. It was found that 16 boundary elements were appropriate. A new pressure equilibrium is performed, attributing the saturation vapour pressure to the boundary elements used to define this new cell and maintaining the exterior boundary conditions. In the next iteration, a new receiver is selected and a new cell is defined. The process is repeated until the pressure at all receivers does not exceed the $P_{\mathrm{s}}$.

The cells are defined by dividing the full domain into small sub-domains, each of which is associated with one 


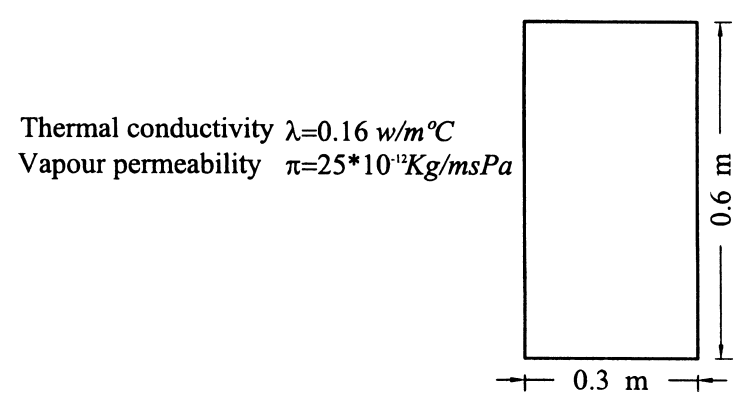

Fig. 1. Geometry of the model.

receiver. In each iteration, a routine check is performed to ascertain if any of the new elements coincides with a previously existing one, in which case both are removed. This procedure is followed because the $P_{\mathrm{w}}$ distribution is being computed outside the zone subject to condensation, that is, outside the sub-domains created by the cells.

After the condensation zone has been delimited, the moisture fluxes inside each cell are computed, using the BEM, prescribing the vapour saturation pressure. Then, the quantification of the amount of liquid water generated is computed from the moisture flux jumps across the boundary of each cell.

\section{Validation of the methodology}

The BEM algorithm is validated by applying it to a two-dimensional rectangular wall (Fig. 1), made of cellular autoclaved concrete, subjected to one-dimensional steadystate heat and vapour pressure diffusion, for which an analytical solution is known.

The boundary conditions are given in Table 1 . In this table the subscripts $i$ and e refer to the indoor and outdoor environment conditions, respectively. To simulate onedimensional heat and moisture diffusion across this wall, null vapour fluxes are assumed to occur across the upper
Table 1

Boundary conditions. One-dimensional model

\begin{tabular}{llll}
\hline $\begin{array}{l}\text { Indoor } \\
\text { temperature }\end{array}$ & $\begin{array}{l}\text { Indoor relative } \\
\text { humidity }\end{array}$ & $\begin{array}{l}\text { Outdoor } \\
\text { temperature }\end{array}$ & $\begin{array}{l}\text { Outdoor relative } \\
\text { humidity }\end{array}$ \\
\hline $18.0{ }^{\circ} \mathrm{C}$ & $90 \%$ & $0.0{ }^{\circ} \mathrm{C}$ & $85 \%$ \\
$P_{\mathrm{S}_{\mathrm{i}}}=2062.83 \mathrm{~Pa}$ & & $P_{\mathrm{s}_{\mathrm{e}}}=610.5 \mathrm{~Pa}$ & \\
$P_{\mathrm{w}_{\mathrm{i}}}=1856.55 \mathrm{~Pa}$ & $P_{\mathrm{w}_{\mathrm{c}}}=518.93 \mathrm{~Pa}$ & \\
\hline
\end{tabular}

and the lower boundaries placed perpendicular to the wall surfaces.

Two additional fictitious layers, one internal $(\lambda=$ $\left.0.1667 \mathrm{~W}^{\circ} \mathrm{C}^{-1} \mathrm{~m}^{-1}\right)$ and the other external $(\lambda=$ $0.5 \mathrm{~W}^{\circ} \mathrm{C}^{-1} \mathrm{~m}^{-1}$ ), each $0.02 \mathrm{~m}$ thick, are added to the two faces of the wall models to simulate the internal and the external thermal surface resistance $\left(1 / h_{\mathrm{i}}=0.12 \mathrm{~m}^{2}{ }^{\circ} \mathrm{C} \mathrm{W}^{-1}\right.$ and $1 / h_{\mathrm{e}}=0.04 \mathrm{~m}^{2{ }^{\circ}} \mathrm{C} \mathrm{W}^{-1}$ ), respectively (Fig. 2a). This procedure allows the radiation and convection contributions to be taken into account. The definition of the vapour pressure across the wall assumes that no variation in vapour pressure occurs between the environment and the surface of the wall. The model therefore does not require the use of fictitious layers (Fig. 2b).

The BEM model is first used to compute the temperature and vapour pressure distribution across the wall over a fine grid of receivers placed as in Fig. 2, equally spaced at 0.01 and $0.02 \mathrm{~m}$ along the horizontal and vertical directions, respectively. Each of the boundaries is modelled using 120 constant elements. Then, the $P_{\mathrm{s}}$ distribution is calculated using Eq. (3). Fig. 3 a shows the variation of $P_{\mathrm{w}}$ and $P_{\mathrm{s}}$. As expected, the variation of $P_{\mathrm{w}}$ is linear across the wall.

As a first step of the iterative process, the difference between the vapour saturation pressure and the vapour pressure is computed (Fig. 3b). Analysis of Fig. 3b confirms the possibility of condensation occurring and the location where it may arise $\left(P_{\mathrm{s}}-P_{\mathrm{w}} \leq 0.0 \mathrm{~Pa}\right)$. Fig. 3a indicates the zone where there is a risk of condensation at the beginning of the process, labelled $C_{\text {risk }}$, where $P_{\mathrm{w}}$ exceeds $P_{\mathrm{s}}$. The receiver at higher risk of condensation is selected. Around this receiver,
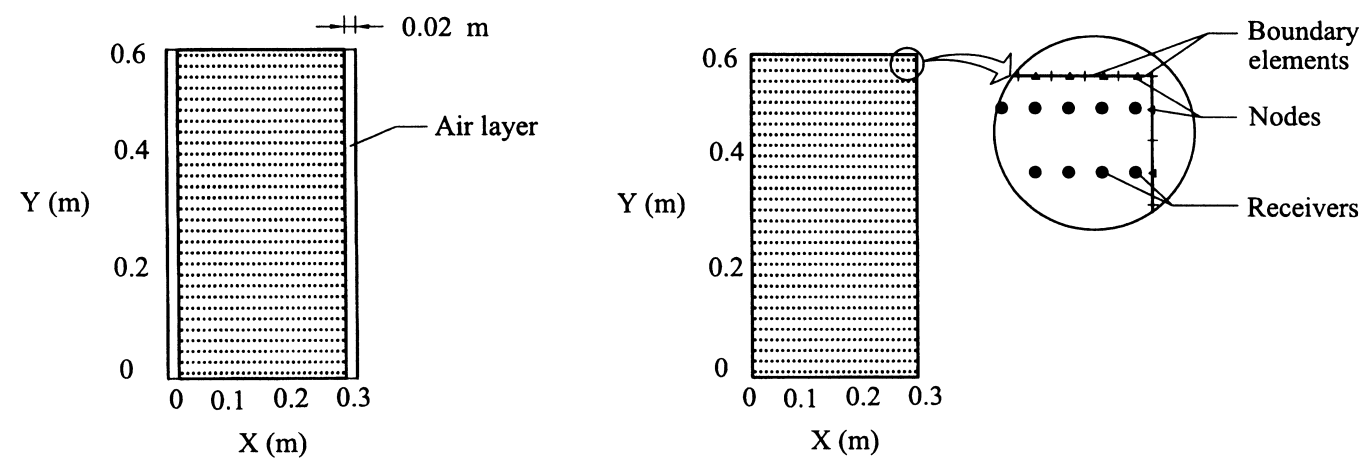

a)

b)

Fig. 2. Boundary geometry and grid of receivers used in the validation model. (a) Temperature model. (b) Vapour pressure model. 


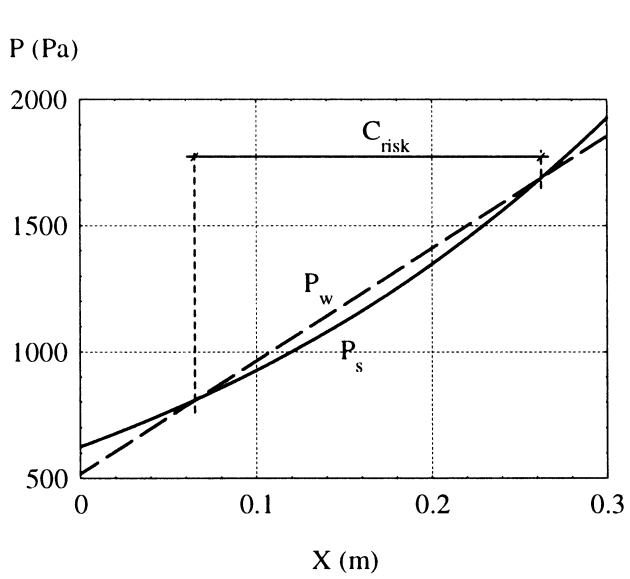

a)

$$
\mathrm{P}_{\mathrm{s}}-\mathrm{P}_{\mathrm{w}}(\mathrm{Pa})
$$

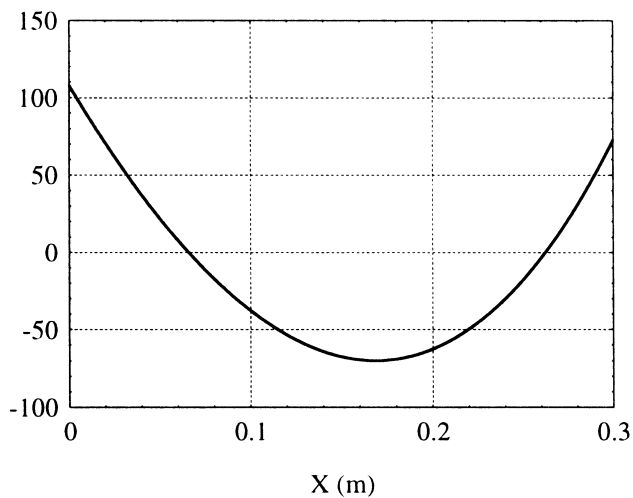

b)

Fig. 3. Initial vapour equilibrium. (a) Vapour saturation pressure distribution, $P_{\mathrm{s}}$, versus first vapour pressure estimation, $P_{\mathrm{w}}$. (b) $P_{\mathrm{s}}-P_{\mathrm{w}}$ distribution.

a rectangular cell is defined with dimensions made equal to the distance between receivers (Fig. 4a). This cell is then discretized with four constant boundary elements, placed on each side of the cell, and the vapour saturation pressure at the nodes is ascribed. A new vapour pressure equilibrium is computed. Fig. $4 \mathrm{~b}$ shows the new difference between $P_{\mathrm{s}}$ and $P_{\mathrm{w}}$. This process is repeated until no receiver registers a vapour pressure above the saturation value.

Figs. 5 and 6 show the results obtained at the end of iterations 3 and 60 . It is quite clear that, at the end of iteration 3, the three sub-domains identified show $P_{\mathrm{w}}$ equal to $P_{\mathrm{s}}$.
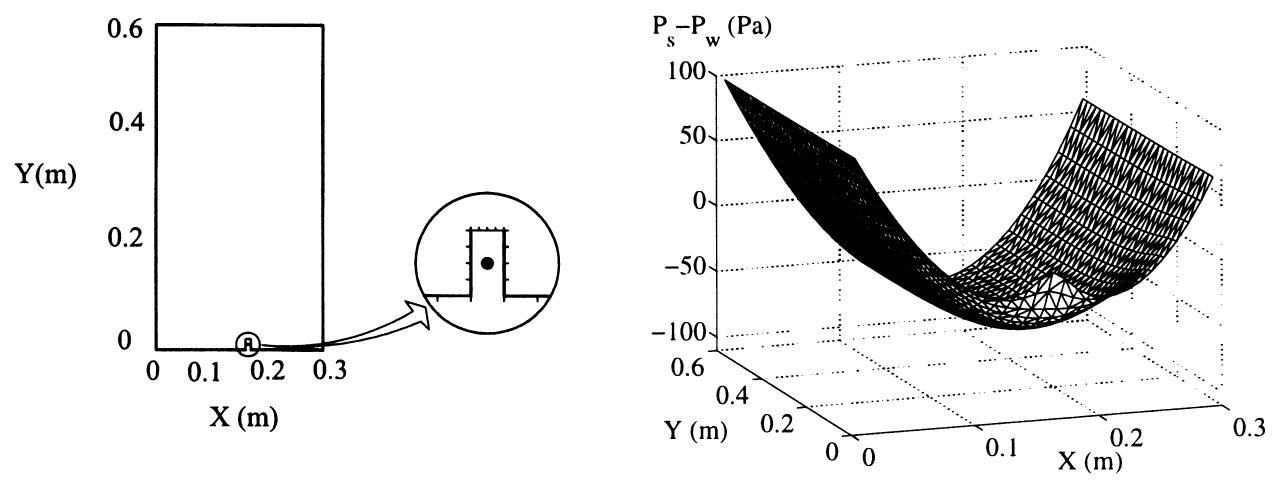

a)

b)

Fig. 4. Results after iteration 1. (a) Cell around the selected receiver. (b) $P_{\mathrm{s}}-P_{\mathrm{w}}$ distribution.
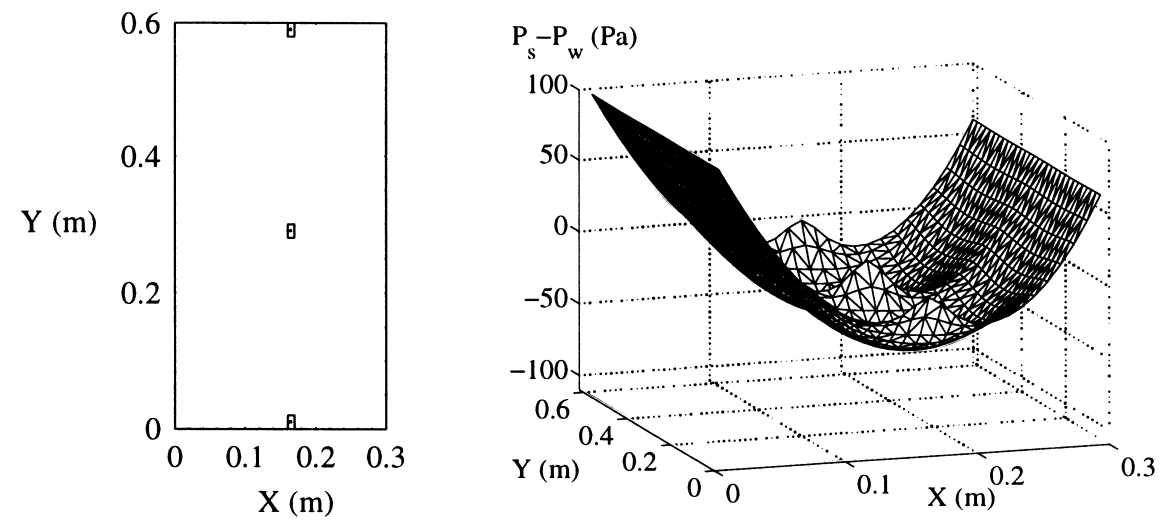

a)

b)

Fig. 5. Results after iteration 3. (a) Selected receivers after iteration 3. (b) $P_{\mathrm{s}}-P_{\mathrm{w}}$ after iteration 3. 

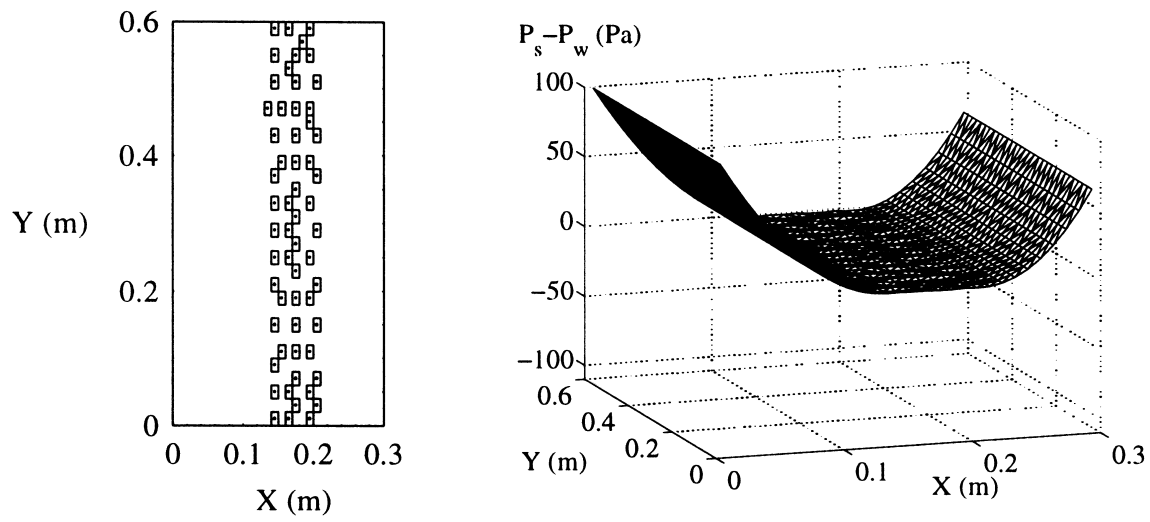

a)

b)

Fig. 6. Results after iteration 60. (a) Selected receivers. (b) $P_{\mathrm{s}}-P_{\mathrm{w}}$ curve.

After iteration 60, the configuration of the condensation patch is very close to the final one, achieved at iteration 240 and shown in Fig. 7. This figure indicates the existence of a condensation zone identified as a rectangular strip located between coordinates $x_{1}=0.135 \mathrm{~m}$ and $x_{2}=$ $0.205 \mathrm{~m}$.

The one-dimensional analytical definition of the condensation zone, which can be computed by imposing pressure flux continuity conditions across the wall $\left(x_{1}=0.136 \mathrm{~m}\right.$ and $\left.x_{2}=0.21 \mathrm{~m}\right)$, represented by

$\left.\frac{\mathrm{d} P_{\mathrm{w}}}{\mathrm{d} x}\right|_{x_{1}^{-}}=\left.\frac{\mathrm{d} P_{\mathrm{s}}}{\mathrm{d} x}\right|_{x_{1}^{+}},\left.\quad \frac{\mathrm{d} P_{\mathrm{w}}}{\mathrm{d} x}\right|_{x_{2}^{+}}=\left.\frac{\mathrm{d} P_{\mathrm{s}}}{\mathrm{d} x}\right|_{x_{2}^{-}}$

where

$\left.\frac{\mathrm{d} P_{\mathrm{w}}}{\mathrm{d} x}\right|_{x_{1}^{-}}=\frac{P_{\mathrm{s}}\left(x_{1}\right)-P_{\mathrm{w} e}}{x_{1}},\left.\quad \frac{\mathrm{d} P_{\mathrm{w}}}{\mathrm{d} x}\right|_{x_{2}^{+}}=\frac{P_{w i}-P_{s}\left(x_{2}\right)}{e-x_{2}}$

and $e$ is the wall thickness confirms a very good approximation of the calculated values obtained by the iterative process [27]. The size $\left(x_{2}-x_{1}\right)$ of the predicted zone obtained by the numerical and analytical scheme is 0.07 and $0.074 \mathrm{~m}$, respectively. Fig. 8a shows the final vapour pressure distribution obtained using the present numerical BEM approach, and the error obtained when these results are compared with the analytical solution is shown in Fig. 8b. The precision of the numerical solution would improve for a finer grid of receivers.

Once the condensation zone is delimited, the amount of liquid water generated is computed, by calculating the moisture flux jumps between the adjacent cells.

Fig. 9 shows the amount of liquid water calculated for each cell as a three-dimensional plot, which indicates the existence of a total of $89.0 \mathrm{mg} \mathrm{m}^{-2} \mathrm{~h}^{-1}$.

To summarise, the iteration process starts by assuming an approximated solution that converges towards the real one. By comparing the initial equilibrium solution (Fig. 3a) with the solution achieved at the last iteration (Fig. 8), one may notice that the condensation risk zone is reduced during the course of the iterative process. The $C_{\text {risk}}$, in this figure,

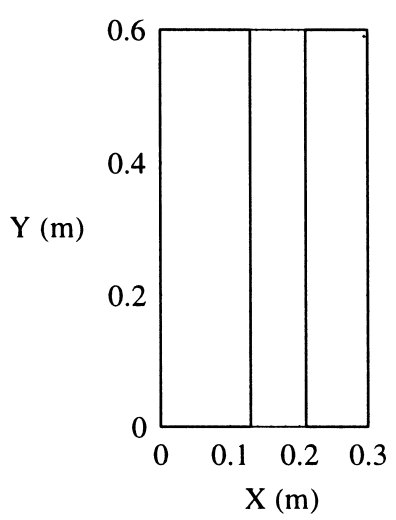

$\mathrm{P}_{\mathrm{s}}-\mathrm{P}_{\mathrm{w}}(\mathrm{Pa})$

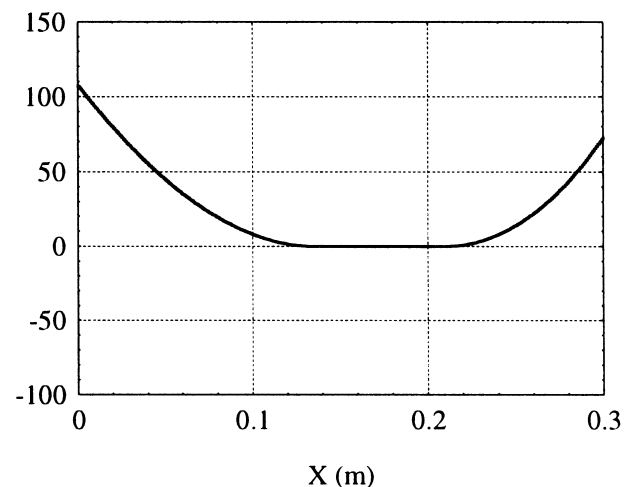

a)

b)

Fig. 7. Results after the final iteration. (a) Final condensation zone. (b) $P_{\mathrm{s}}-P_{\mathrm{w}}$ at the end of iteration process. 


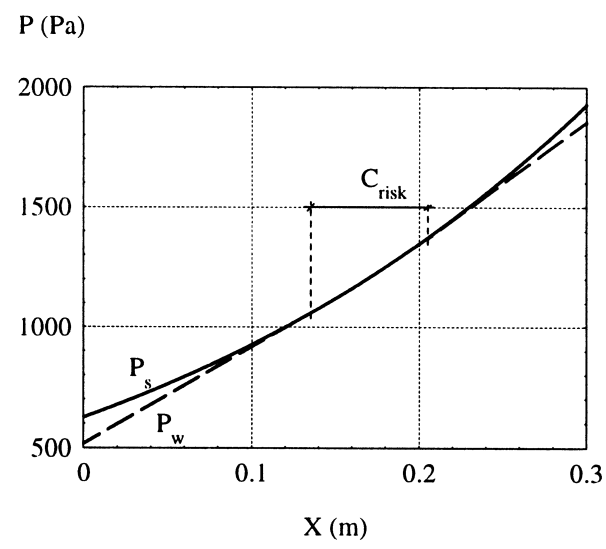

a)

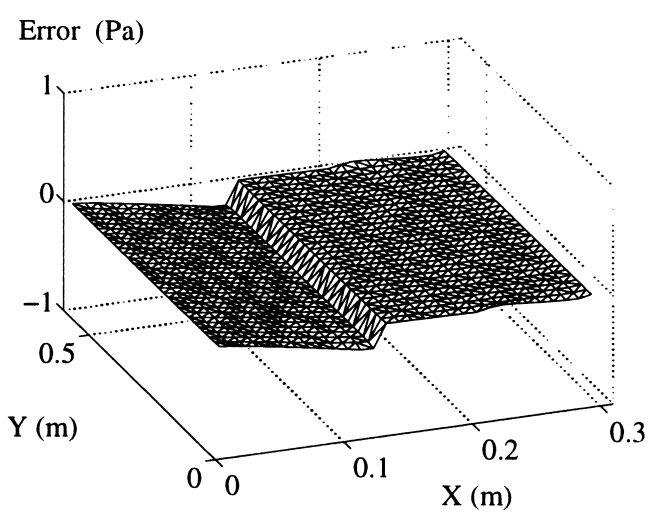

b)

Fig. 8. Results after the final iteration. (a) Vapour saturation pressure distribution, $P_{\mathrm{s}}$, versus final vapour pressure estimation, $P_{\mathrm{w}}$. (b) BEM error.

indicates the zone where $P_{\mathrm{w}}$ and $P_{\mathrm{s}}$ are equal, that is, where condensation occurs.

\section{Applications}

To illustrate the applicability of the proposed method, a two-dimensional model with a T-shaped geometry is analysed, as shown in Fig. 10. It represents the separation between two adjacent rooms and the outdoor environment. The construction element is assumed to be made of cellular autoclaved concrete, with the thermal conductivity and vapour permeability as given in this figure.

Three different temperature and moisture conditions are studied, as listed in Table 2. Null fluxes are ascribed to the boundaries perpendicular to the wall surfaces for all models.

This table defines the temperature and relative humidity conditions that have been selected to generate internal condensation. These hygrothermal conditions are frequently found both inside and outside Portuguese dwellings.

Three different cases are used to illustrate the practical

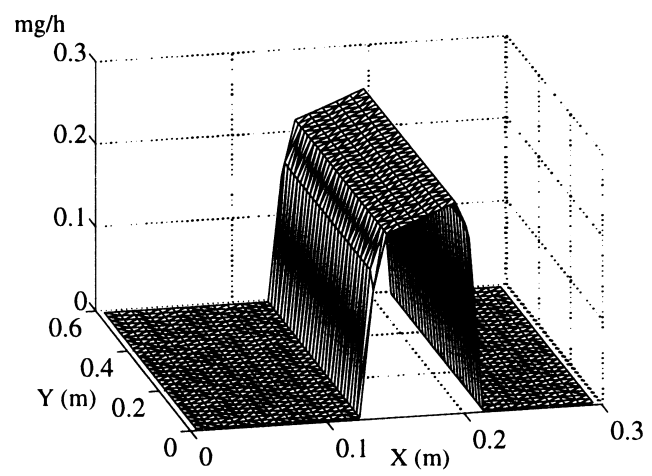

Fig. 9. Liquid water generated by condensation. importance of the present model in the definition of condensation within two-dimensional construction elements. The first model assumes that rooms $\mathrm{A}$ and $\mathrm{B}$ have the same temperature $\left(18{ }^{\circ} \mathrm{C}\right)$ and moisture conditions $(90 \%$ relative humidity). The second model ascribes outdoor environmental conditions to room $\mathrm{B}\left(0{ }^{\circ} \mathrm{C}, 85 \%\right.$ relative humidity). The third model illustrates the situation where the room B is assumed to be unheated (temperature $10{ }^{\circ} \mathrm{C}$ and $85 \%$ relative humidity).

The boundary discretization and the grid of receivers (1350), equally spaced at $0.02 \mathrm{~m}$ apart, used to solve both the temperature and pressure distributions are shown in Fig. 11a and b, respectively. A fictitious air layer along the wall surfaces is used to simulate the internal and external thermal surface resistance, when the temperature equilibrium is performed. The model used to compute the vapour pressure does not require the use of additional layers because it is assumed that no variation in vapour pressure occurs between the environment and the surface of the wall. These assumptions are frequently accepted for the hygrothermal design of buildings. Thus, a total of 816 constant

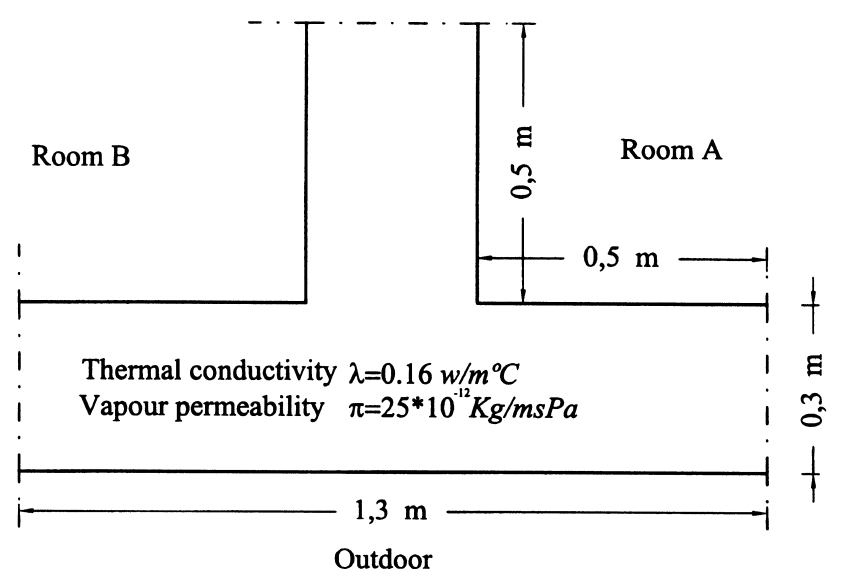

Fig. 10. Geometry of the model. 
Table 2

Boundary conditions. T-shaped models

\begin{tabular}{|c|c|c|c|c|c|c|}
\hline & \multicolumn{2}{|l|}{ Room A } & \multicolumn{2}{|l|}{ Room B } & \multicolumn{2}{|l|}{ Outdoor } \\
\hline & Temperature & $\begin{array}{l}\text { Relative } \\
\text { humidity }\end{array}$ & Temperature & $\begin{array}{l}\text { Relative } \\
\text { humidity }\end{array}$ & Temperature & $\begin{array}{l}\text { Relative } \\
\text { humidity }\end{array}$ \\
\hline Case 1 & $\begin{array}{l}18.0^{\circ} \mathrm{C} \\
P_{\mathrm{s}}=2062.83 \mathrm{~Pa} \\
P_{\mathrm{w}}=1856.55 \mathrm{~Pa}\end{array}$ & $90 \%$ & $\begin{array}{l}18.0^{\circ} \mathrm{C} \\
P_{\mathrm{s}}=2062.83 \mathrm{~Pa} \\
P_{\mathrm{w}}=1856.55 \mathrm{~Pa}\end{array}$ & $90 \%$ & $\begin{array}{l}0.0^{\circ} \mathrm{C} \\
P_{\mathrm{s}}=610.5 \mathrm{~Pa} \\
P_{\mathrm{w}}=518.93 \mathrm{~Pa}\end{array}$ & $85 \%$ \\
\hline Case 2 & $\begin{array}{l}18.0^{\circ} \mathrm{C} \\
P_{\mathrm{s}}=2062.83 \mathrm{~Pa} \\
P_{\mathrm{w}}=1856.55 \mathrm{~Pa}\end{array}$ & $90 \%$ & $\begin{array}{l}0.0^{\circ} \mathrm{C} \\
P_{\mathrm{s}}=610.5 \mathrm{~Pa} \\
P_{\mathrm{w}}=518.93 \mathrm{~Pa}\end{array}$ & $85 \%$ & $\begin{array}{l}0.0^{\circ} \mathrm{C} \\
P_{\mathrm{s}}=610.5 \mathrm{~Pa} \\
P_{\mathrm{w}}=518.93 \mathrm{~Pa}\end{array}$ & $85 \%$ \\
\hline Case 3 & $\begin{array}{l}18.0^{\circ} \mathrm{C} \\
P_{\mathrm{s}}=2062.83 \mathrm{~Pa} \\
P_{\mathrm{w}}=1856.55 \mathrm{~Pa}\end{array}$ & $90 \%$ & $\begin{array}{l}10.0^{\circ} \mathrm{C} \\
P_{\mathrm{s}}=1227.31 \mathrm{~Pa} \\
P_{\mathrm{w}}=1043.21 \mathrm{~Pa}\end{array}$ & $85 \%$ & $\begin{array}{l}0.0^{\circ} \mathrm{C} \\
P_{\mathrm{s}}=610.5 \mathrm{~Pa} \\
P_{\mathrm{w}}=518.93 \mathrm{~Pa}\end{array}$ & $85 \%$ \\
\hline
\end{tabular}

boundary elements is needed to discretize the boundary, while only 645 constant boundary elements are used to compute the vapour pressure equilibrium.

Fig. 12 shows both the condensation patches and the amount of liquid water generated at the end of the iterative process for all models analysed. The condensation zone in model 1 (Fig. 12a) is located in the outside wall, with a symmetrical distribution in relation to the interior. It can be seen that the condensation reaches the interior face of the exterior wall in the vicinity of the inner corners. The amount of liquid water near the surface was calculated assuming null vapour pressure flux in the boundary elements. The plot of liquid water generated reflects this behaviour by allocating a larger amount of water in the vicinity of these corners. The amount of liquid water produced is reduced over the symmetry axis, due to the presence of the interior wall, which allows the temperature to fall and, consequently, the vapour saturation pressure to diminish. Further from the corners, the heat and pressure flux distributions approach the results of a one-dimensional model. Notice that another type of moisture flux condition may easily be incorporated in the model. The condensation zone would be the same for any condition, with only the amount of liquid water generated at the surface being smaller.

Fig. $12 \mathrm{~b}$ shows the results obtained with model 2 . The condensation patch occurs along the entire wall that separates room A from both the room B and the outdoor environment. This behaviour was expected, since the same variable conditions have been ascribed to these latter two surfaces. Given the concentration of fluxes in the corner of room A, condensation occurs in its vicinity, and the model behaves there like a thermal bridge. A larger amount of water is then generated around this singularity. The width of the condensation zone away from the corner matches that of the previous example.

Fig. $12 \mathrm{c}$ refers to the results of model 3. On comparing these results with the previous cases, we can see that the condensation zone is smaller. In the inner corner, the condensation patch still extends up to the interior face of the wall, but the liquid water is now generated in smaller amounts. This can be explained by the fact that the hygrothermal conditions ascribed to room B (unheated room) do not lead to condensation, either in the wall separating the heated room (room A) or in the wall separating the outdoor environment.
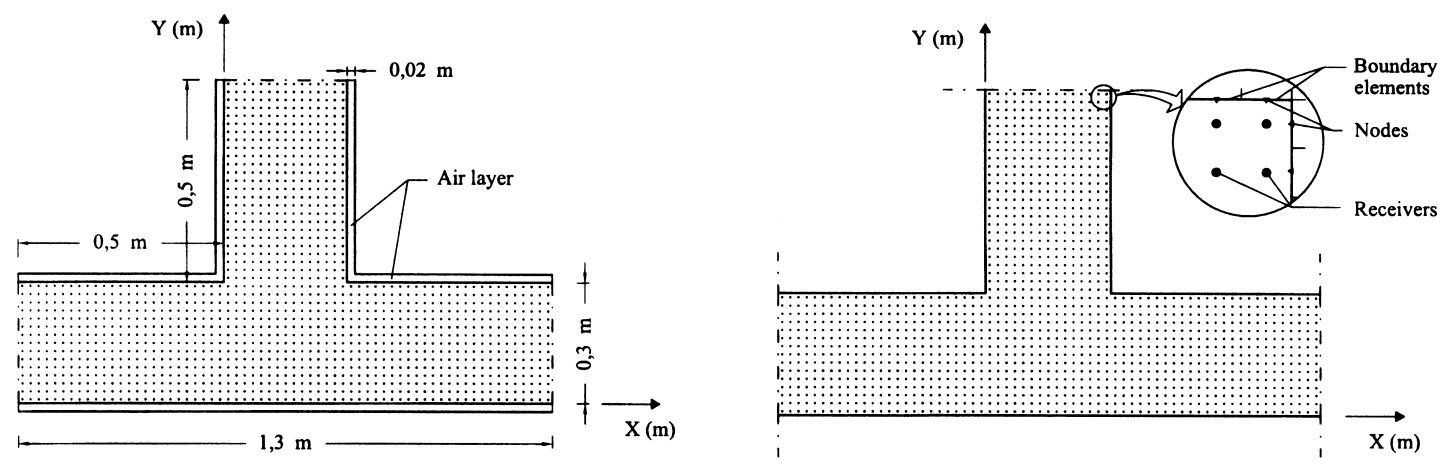

a)

Fig. 11. Boundary discretization and grid of receivers. (a) Temperature model. (b) Vapour pressure model. 
Condensation zone
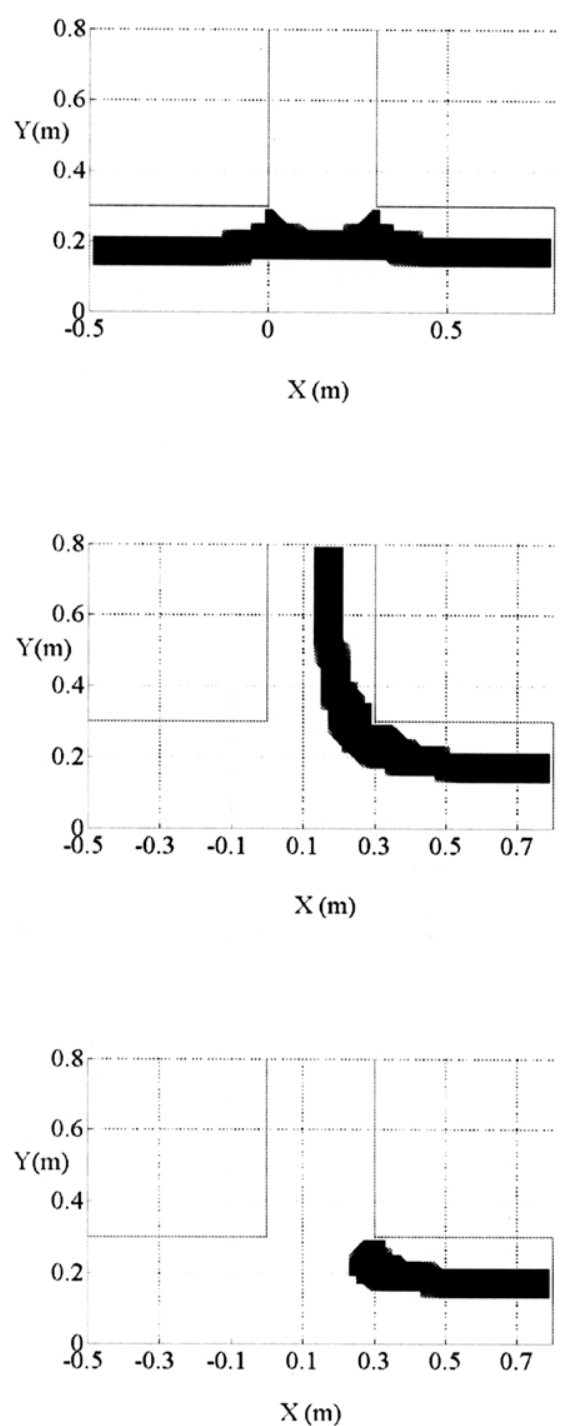

Liquid water generated

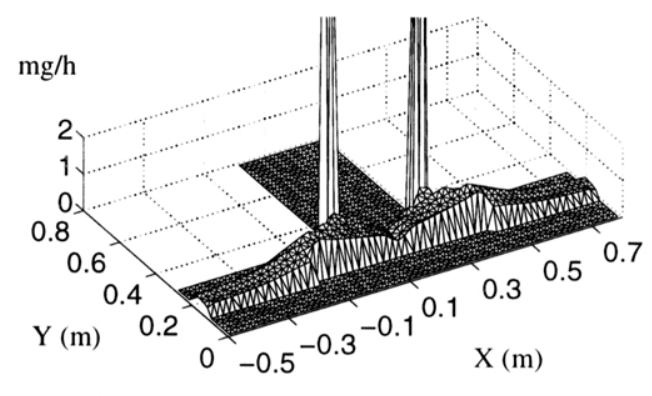

a)

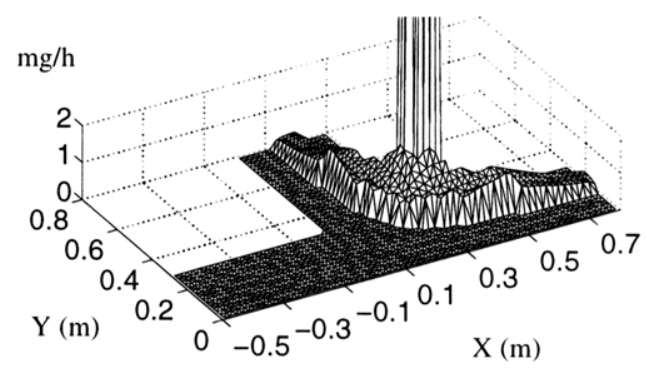

b)

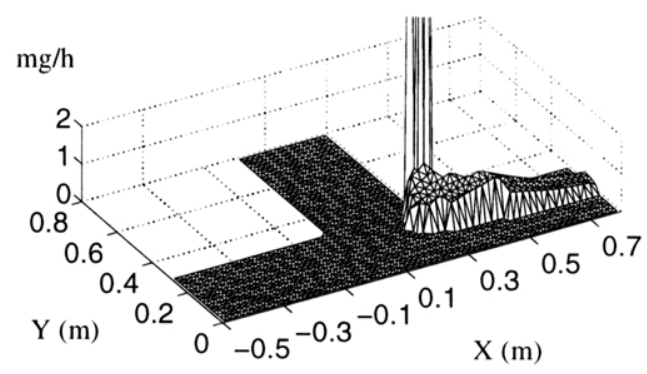

c)

Fig. 12. Condensation and liquid water generated: distribution results. (a) Case 1. (b) Case 2. (c) Case 3.

These results underscore the importance of studying singular zones in walls, like corners or intersections, where condensation tends to be concentrated and where a one-dimensional model does not apply.

\section{Conclusions}

The Boundary Elements Method (BEM) has been formulated and implemented to solve two-dimensional steady-state heat conduction and vapour diffusion problems efficiently.

The present work proposes an iterative BEM process to identify the zones where there is the risk of condensation inside construction elements. The proposed method also calculates the amount of liquid water generated by condensation. The iterative process first establishes a vapour pressure equilibrium state. The vapour pressure at each internal point is then compared with the corresponding vapour saturation pressure. The receiver where the vapour pressure exceeds the vapour saturation pressure by the greatest amount is removed from the domain, and a cell is defined ascribing as boundary conditions the vapour saturation pressure in each node. The BEM is computed over this modified model, and the iterative process continues until the vapour saturation pressure is not exceeded inside the domain. This technique was validated by applying it to a one-dimensional problem for which an analytical solution is 
known. The method provides an accurate identification of the condensation zone. The amount of water generated, calculated using the one-dimensional model, gives a good approximation to the analytical solution.

The applicability of the proposed method was demonstrated by defining the condensation zone and the amount of liquid water generated on a T-shaped wall, subjected to different boundary conditions. Meanwhile, the results suggest that the use of simplified one-dimensional analysis in the presence of singularities may lead to misinterpretation of the condensation phenomena, which may be prevented by the use of the proposed model.

\section{Acknowledgements}

The authors would like to thank Professor Vasco Freitas of the University of Porto for his valuable contributions during the course of this research.

\section{References}

[1] Freitas V. Condensations in Portuguese Buildings. Proceedings of the International Symposium on Moisture Problems in Building Walls, Porto, Portugal; 1995. p. 75-85.

[2] Hagentoft CE. Introduction to building physics. Sweden: Studentlitteratur, 2001.

[3] Glaser H. Vereinfachte Berechnung der Dampfdiffusion durch geschichtete Wände bei Ausscheidung von Wasser und Eis. Kältetechnik 1958;10.

[4] Glaser H. Vereinfachte Berechnung der Dampfdiffusion durch geschichtete Wände bei Ausscheidung von Wasser und Eis. Kältetechnik 1958;11:358-64.

[5] Glaser H. Vereinfachte Berechnung der Dampfdiffusion durch geschichtete Wände bei Ausscheidung von Wasser und Eis. Kältetechnik 1958;12:386-90.

[6] Krischer O, Kast W. Die wissenschaftlichen Grundlagen der Trocknungstechnik, Dritte Auflage. Berlin: Springer-Verlag, 1978.

[7] Luikov AV. Systems of differential equations of heat and mass transfer in capillary-porous bodies. Int J Heat Mass Transf 1975;18:1-14.

[8] Philip JR, De Vries DA. Moisture movement in porous materials under temperature gradients. Trans Am Geophys Union 1957;2:222-32.

[9] Carslaw HS, Jaeger JC. Conduction of heat in solids. 2nd ed. Oxford: Oxford Science Publications/Clarendon Press, 1997.
[10] Crank J. The mathematics of diffusion. 2nd ed. Oxford: Oxford Science Publications/Clarendon Press, 1999.

[11] Gebhart B. Heat conduction and mass diffusion. Singapore/New York: International Editions/McGraw-Hill, 1993.

[12] Kieß1 K. Kapillarer und dampfförmiger Feuchtetransport in mehrschichtigen Bauteilen. Dissertation Universität-Gesamthochschule Essen; 1983.

[13] Kieß1 K, Gertis K. Feuchtetransport in Baustoffen. Forschungsberichte aus dem Fachbereich Bauwesen, no. 13, Dissertation Universität-Gesamthochschule Essen; 1980.

[14] Künzel HM. Simultaneuous heat and moisture transport in building components. One- and two-dimensional calculation using simple parameters. Stuttgart: IRB Verlag, 1995.

[15] DIN 4108. Wärmeschutz im Hochbau. DIN Deutsches Institut für Normung; 1981.

[16] GTR WI 46, CEN/TC 89 WI29. prEN ISO 13788. Hygrothermal performance of building components and building elements. Internal surface temperature to avoid critical surface humidity and interstitial condensation. Calculation methods. The International Organization for Standardization and European Committee for Standardization; 1999.

[17] Bathe KJ. Numerical methods in finite element analysis. Englewood Cliffs, NJ: Prentice-Hall, 1976.

[18] Freitas VP, Abrantes V, Crausse P. Moisture migration in building walls. Analysis of the interface phenomena. Building Environ 1996;31(2):99-108.

[19] Mingfang T, Qigao C. Numerical simulation of thermal performance of a square column. Building Environ 1997;32(5):411-5.

[20] Fratantonio M, Rencis JJ. Exact boundary element integrations for two-dimensional Laplace equation. Engng Anal Boundary Elem 2000;24(4):325-42.

[21] Kassab AJ, Divo E. A generalized boundary integral equation for isotropic heat conduction with spatially varying thermal conductivity. Engng Anal Boundary Elem 1996;18(4):273-86.

[22] Ochiai Y, Sekiya T. Steady-state heat conduction analysis by improved multiple-reciprocity boundary element method. Engng Anal Boundary Elem 1996;18(2):111-7.

[23] Melnikov YA. An alternative construction of Green's Function for the two-dimensional heat conduction. Engng Anal Boundary Elem 2000;24(6):467-75.

[24] British Standard Code of Practice for Control of Condensation in Buildings-BS5250. British Standards Institute, UK; 1989.

[25] Manolis GD, Beskos DE. Boundary element methods in elastodynamics. London: Unwin Hyman, 1988.

[26] Brebbia CA, Dominguez J. Boundary elements. An introductory course. New York/Boston: Computational Mechanics Publications/ McGraw-Hill, 1989.

[27] Couasnet Y. Les Condensations dans les Bâtiments—Guide Pratique et Éléments D'Analyse. Paris: Presses de L'École Nationale des Ponts et Chaussées, 1990. 